\title{
Effect of concrete surface treatment on adhesion in repair systems
}

\author{
A. Garbacz*, M. Górka* and L. Courard † \\ Warsaw University of Technology; University of Liege
}

\begin{abstract}
Existing concrete surfaces need to be roughened to a profile necessary to achieve mechanical interlocking with any repair material. In this study, different surface treatments (e.g. grinding, sandblasting, shotblasting, hand- and mechanical milling) were performed and the quality of the preparation established on the basis of three main parameters: surface geometry, superficial concrete microcracking and adhesion. Surface geometry was characterised on the basis of the measurement of surface profile-profilometry-and the analysis of statistical and amplitude parameters calculated from the waviness (lower frequencies) and the roughness (higher frequencies) profiles of the surface. Investigations were also performed to assess the quality of the superficial zone of concrete and cracks were systematically observed in relation to surface treatment where both scanning electron microscopy and light microscopy were used for analysis. Finally, a repair mortar, with or without bond coat, was applied to the concrete substrates in order to measure adhesion. Relationships clearly show the effect of roughness on adhesion in the case where no bond coat was used and also the influence of the power of the surface treatment on the waviness shape of the profile and the presence of microcracks in the near-surface layer, related to failure type.
\end{abstract}

\section{Introduction}

The adhesion between overlays and concrete substrate is one of the most important factors that affect the reliability and durability of repair. ${ }^{1,2}$ High adhesion causes higher tolerance on non-compatibility of properties of both materials. ${ }^{3}$ A pull-off strength higher than $1.5 \mathrm{MPa}$ is recommended in many standards and guidelines. $^{4-8}$ The adhesion depends on many phenomena taking place at the interface zone ${ }^{9-11}$ for example, bond-detrimental layers (including bleeding), wettability of concrete substrate by repair materials, secondary physical attraction forces induced in the system, roughness of surface (interlocking mechanism), and moisture content in the concrete substrate versus the repair system (e.g. cement concrete or polymer composite).

The aim of the treatment of surface concrete is to remove any type of layer that causes a decrease in

* Institute of Construction Engineering \& Management, Faculty of Civil Engineering, Warsaw University of Technology, PL-00-637 Warsaw, Poland

$\dagger$ Department GeomaC, Building Materials Research Unit, University of Liege, Mechanical and Civil Engineering Institute, Chemin des Chevreuils, 1 (Bât. B 52/3), B - 4000 Liege (Belgium)

(MCR 1233) Paper received ???;

last revised ???; accepted ??? adhesion as well as to enlarge the area of contact surface by increasing surface roughness. Depending on local conditions of the specific building, surface roughness is obtained after sandblasting, milling, grinding, hydro-jetting or shotblasting. The chosen technique and the level of energy applied induce many different shapes and configurations. The effect of concrete surface roughness on adhesion is not quite clear. ${ }^{12-15}$ Fiebrich $^{9}$ has shown that there is a relationship between the percentage of the surface of aggregates at the level of the concrete substrate after treatment and the adhesion of gunite; the best results were obtained for ratios between $30 \%$ and $40 \%$ of visible aggregates. Silfwerbrand ${ }^{16}$ showed that the influence of roughness is quite low. By comparing sandblasting and hydrojetting effects, the values of adhesion strength are quite similar, even if the amount of adhesive rupture is higher for sandblasting. However, Fukuzawa ${ }^{17}$ has shown that there was a correlation between adhesion strength and some roughness parameters. Finally, a few authors ${ }^{12,18}$ have concluded that surface roughness itself does not have significant influence but microcracks induced by surface treatment ${ }^{19}$ will mainly contribute to the deterioration of bond quality. The effect of a bond coat (PC or PCC type) is also under discussion. According to the present authors' opinion, ${ }^{16,18}$ the bond coat should be avoided because of creation of an extra 
plane of weakness. Moreover, bond coat could have a negative effect with very rough surfaces because it could limit a good interlocking effect between substrate and repair material. ${ }^{16}$ However, some authors have shown that a presence of bond coat can significantly increase the adhesion. $13,14,20$

It is obvious, then, that no clear relationship has been established between adhesion and surface preparation. The aim of this study is to evaluate the effect of confcrete surface treatment on adhesion in a multi-layer system. Several mechanical methods of concrete surface preparation were selected to obtain various qualities of the surface concrete substrate. The quantification of surface roughness has been evaluated using mechanical profilometry. $^{21}$

\section{Experiment}

\section{Materials and treatment type}

The concrete substrates $(30 \times 30 \times 5 \mathrm{~cm})$ of $\mathrm{C} 20 / 25$ class were made from the concrete mix: CEM I 32.5 , 2/8 limestone, $0 / 2$ quartz sand. The concrete substrates were prepared by the following types of the mechanical treatment

(a) grinding (GR)

(b) sandblasting (SB)

(c) shotblasting (treatment time: $20 \mathrm{~s}$ (SHB20), $35 \mathrm{~s}$ (SHB35) and $45 \mathrm{~s}$ (SHB45))

(d) milling (by hand (HMIL) and mechanically (MMIL)).

Additionally, the concrete samples without treatment (NT) were tested as the control samples.

The commercial repair mortar of PCC-type reinforced with glass microfibres and, as recommended by the producer, the PCC bond coat (Table 1) was used to prepare the overlays. The overlay was applied to the concrete substrate after various mechanical treatments in accordance with the producer's guidelines, with and without the bond coat. The 16 various combinationseight preparation techniques and the bond coat-were tested. Three plates for each combination system were prepared. The adhesion was evaluated with the pull-off test (acc EN 12636:2001) after 28 days of curing.

\section{Characterisation of concrete surface roughness}

There are several methods for surface roughness description. ${ }^{9,18,22-25}$ In this work, the surface roughness of concrete was described with profilometry analysis. The basic problem with the implementation of profilometry to the concrete surfaces after various treatments is a large variation in their roughness. In this study an evaluation of concrete surface roughness was carried out with a commercial test device composed of a stylus, a conditioner/amplifier, a mechanical unit for advancement and a computer unit for data acquisition. The registered profiles were first transformed to remove effect of the profile orientation ('shape' filtration). On the basis of the total profile obtained (Fig. 1(a)), parameters of Abbott's curve were calculated (Fig. 1(b)). The total profile was then filtered and divided into low and high frequencies to separate parameters of waviness (Fig. 1(c)) and roughness (Fig. 1(d)), respectively. The details of signal treatment are given elsewhere. $^{21}$

At the first step, roughness of the profile was analysed. In this case, a stylus with a diamond sphere radius of $6 \mu \mathrm{m}$ was used. The length of measurement was $8 \mathrm{~mm}$ and the filter used to separate roughness from the total profile was fixed to $0.8 \mathrm{~mm}$. The measurement of waviness was made with another stylus $79 \mathrm{~mm}$ long and a diamond of $1.5 \mathrm{~mm}$ radius. The length of the measurement was enlarged to $30 \mathrm{~mm}$ or more. The chosen filter to separate waviness from the total profile was $0.8 \mathrm{~mm}$. In all cases, three profiles were registered on one sample of each kind of preparation, and each profile on one sample was measured in different directions. The parameters of Abbott's curve $\left(C_{\mathrm{R}}, C_{\mathrm{F}}, C_{\mathrm{L}}\right)$, the waviness parameters $\left(W_{\mathrm{a}}, W_{\mathrm{t}}, W_{\mathrm{p}}\right)$, and the roughness parameters $\left(R_{\mathrm{a}}, R_{\mathrm{t}}, R_{\mathrm{p}}\right)$ were used for the

Table 1. Characteristics of the repair materials used (acc. producer's technical data)

\begin{tabular}{|c|c|c|}
\hline Property & Bond coat & Repair mortar \\
\hline Composition & $\begin{array}{l}\text { Crack-bridging polymer modified cement mortar } \\
\text { of PCC type }\end{array}$ & $\begin{array}{l}\text { Polymer modified cement mortar of PCC type } \\
\text { containing glass microfibres }\end{array}$ \\
\hline Maximum grain size of aggregate: $\mathrm{mm}$ & 0.5 & $2 \cdot 0$ \\
\hline Mix proportion: mortar/water by mass & $2 \cdot 8: 1$ & $8 \cdot 3: 1$ \\
\hline Compressive strength: $\mathrm{MPa}$ & - & $>40$ \\
\hline Flexural strength: $\mathrm{MPa}$ & - & $>10$ \\
\hline Pull-off strength: MPa & \multirow{2}{*}{\multicolumn{2}{|c|}{$\begin{array}{l}\text { Without bond coat }>1.5 \\
\text { With bond coat }>2 \cdot 0 \\
\text { Clean, sound with tensile strength higher than } 1.5 \mathrm{MPa} \\
\text { Suggested way of concrete substrate preparation: shotblasting, water-jet or thermal } \\
\text { Concrete substrate should be moist; in the case of bond coat presence the repair mortar should be } \\
\text { placed directly on fresh bond coat }\end{array}$}} \\
\hline $\begin{array}{l}\text { Requirements for concrete substrate } \\
\text { preparation } \\
\text { Application }\end{array}$ & & \\
\hline
\end{tabular}


(a)

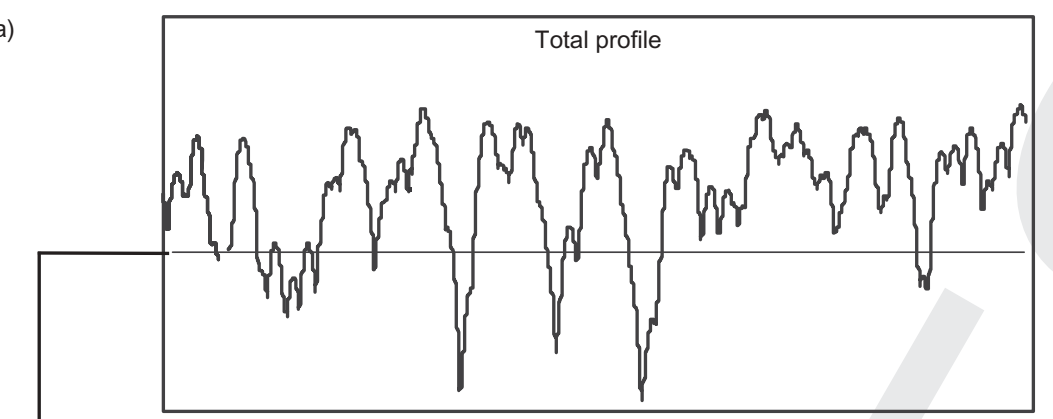

(b)

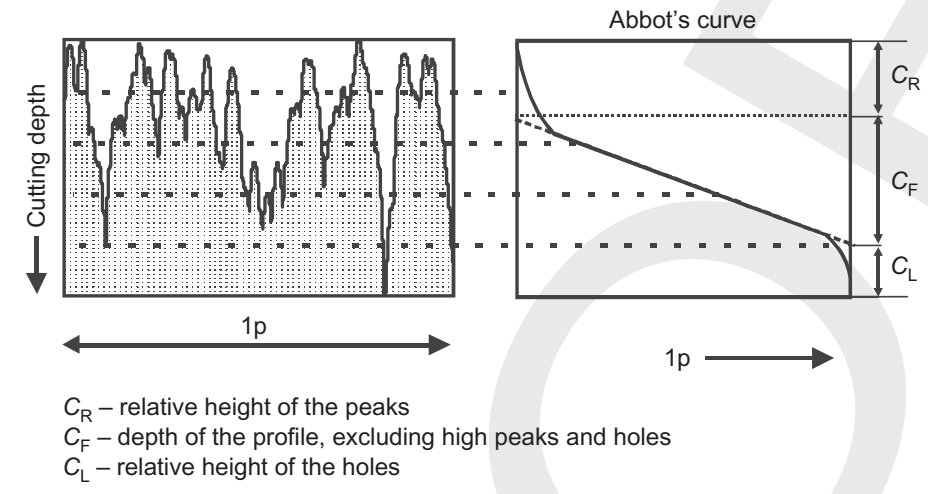

(c)
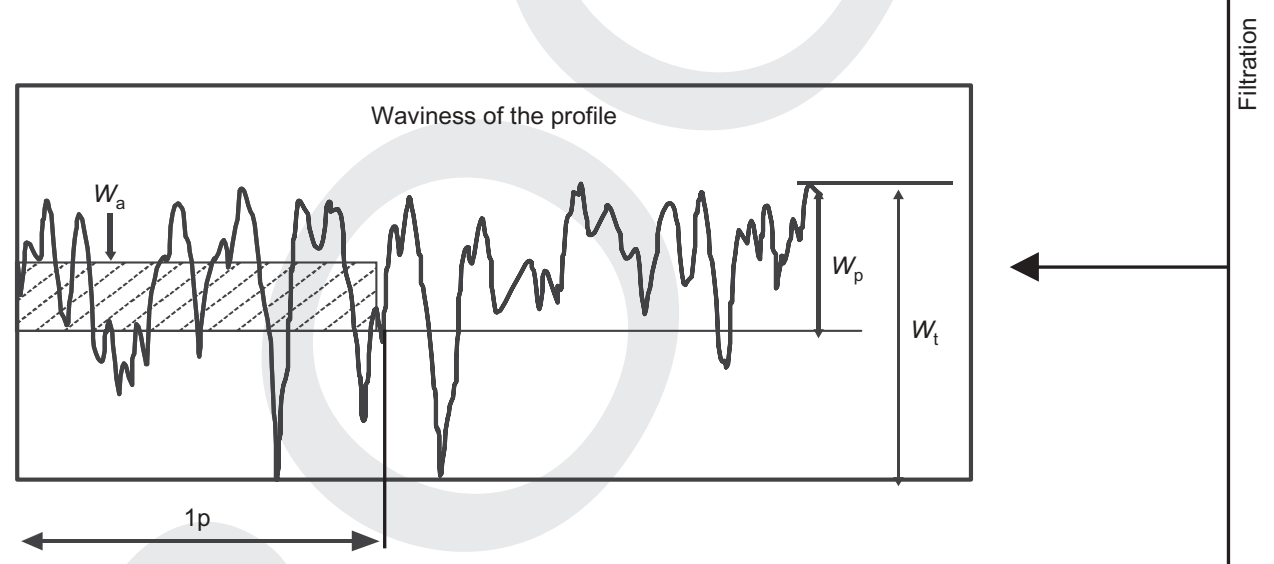

$W_{\mathrm{t}}=$ total height of the waviness profile

$W_{\mathrm{a}}=$ arithmetic mean of the deviation of the waviness profile from the mean line

$W_{\mathrm{p}}=$ maximum height of the waviness profile

(d)

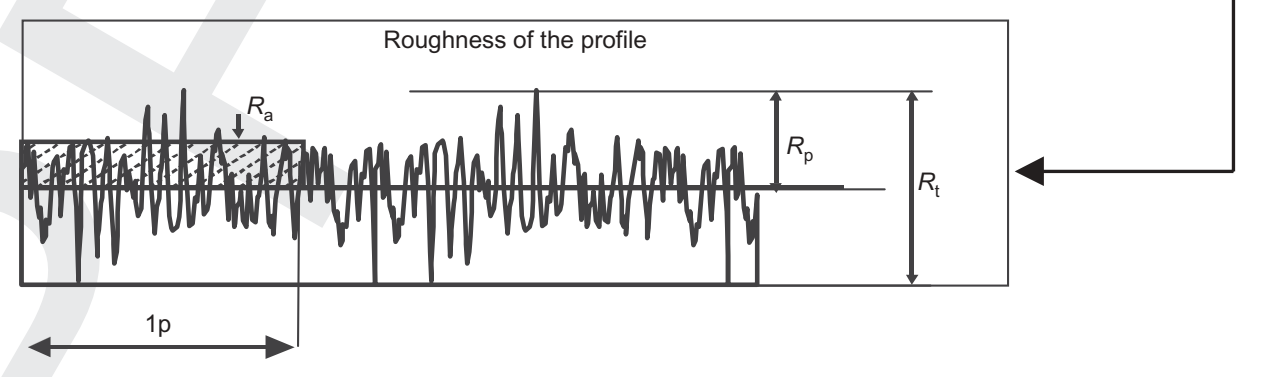

$R_{\mathrm{t}}=$ total height of the roughness profile

$R_{\mathrm{a}}=$ arithmetic mean of the deviation of the roughness profile from the mean line

$R_{\mathrm{p}}=$ maximum height of the roughness profile

Fig. 1. Parameters of profile analysis used in this work: (a) total profile; (b) Abbott's curves and parameters; (c) waviness profile; and (d) roughness profile 
characterisation of surfaces after various treatments. Surfometry analyses realised in the same conditions on a series of profiles measured at $300 \mu \mathrm{m}$ gives a threedimensional (3-D) representation of the surfaces.

\section{Results}

\section{Concrete surface quality}

The results obtained for surface roughness evaluation as well as the observation of the microstructure with a scanning electron microscope (SEM) showed that concrete surfaces were significantly different after various treatments (Table 2). On the basis of the results, the following conclusions can be drawn.

(a) The waviness parameters are about 5\% smaller than the corresponding ones deduced from the total profile parameters for all types of treatment. This confirmed that the heights and holes of the total profile have not been 'cut' too much and the global shape of the profile has been preserved through the waviness.

(b) The 'roughest' surface was obtained after shotblasting (45 s) and the least rough for the sample without treatment. The waviness parameters $W_{\mathrm{t}}, W_{\mathrm{a}}$ and $W_{\mathrm{p}}$ increased from five times for grinding up to 80 times for shotblasting compared with the roughness of concrete surface without treatment (Fig. 2).

(c) The parameters of Abbott's curve were rising in the same order as the waviness parameters (Fig. 3). This means that the more aggressive method of concrete treatment makes the profile more rough, the relative height of the peaks is larger $\left(C_{\mathrm{R}}\right)$ as well as the depth of the profile $\left(C_{\mathrm{F}}\right)$ and the relative height of the holes $\left(C_{\mathrm{L}}\right)$. Abbott's curves show that the surfaces prepared by grinding, sandblasting as well as hand-milling have a similar geometry to the formworked concrete surface in which the roughness is relatively low. The surfaces resulting from shotblasting (20 and $35 \mathrm{~s}$, respectively) and after mechanical milling belong to the second group of surface geometry with medium roughness. Significantly rougher surfaces with large peaks and holes were obtained after shotblasting for $45 \mathrm{~s}$.

(d) The value of waviness parameters and parameters of Abbott's curve increase with the time of shotblasting and when hand-milling is replaced by mechanical milling.

(e) The roughness parameters $R_{\mathrm{a}}, R_{\mathrm{p}}$ and $R_{\mathrm{t}}$ were twoand-a-half to four times higher than those obtained for the formworked concrete surface. There was no significant difference for roughness parameters between grinding, sandblasting, milling and shotblasting. This behaviour was already observed for the comparison between sandblasted and polished concrete surfaces. ${ }^{22}$ Moreover, roughness parameters for sandblasted surfaces are very close to those determined by Courard ${ }^{22}$ with the same stylus for quite different concrete; for example, $R_{\mathrm{a}}$ was equal to 15 and $16 \mu \mathrm{m}$, respectively. The results confirm that the surface treatment technique has no major influence on the micro-roughness ('high-frequency waves') of the profile (Fig. 4).

\section{Pull-off strength}

The results of pull-off strength measurements (Table 3) for the overlays prepared with bond coat in accordance with producer's technical data, were relatively close to each other: $1.4 \mathrm{MPa}$ being the lowest value and $2.0 \mathrm{MPa}$ being the highest. In 'bond coat' group, the highest pull-off strength was obtained for the samples after shotblasting and sandblasting as well as the samples without treatment. The lowest value in this group (1.4 MPa) was obtained for samples prepared by milling.

The application of the overlay without the bond coat generally induced a decrease in pull-off strength. The lowest value ( $0.5 \mathrm{MPa})$ was obtained for concrete after mechanical milling. For sandblasted and untreated samples, the lack of bond coat did not induce significant changes in the pull-off strength values. In general, the application of the bond coat caused the decrease of the coefficient of variation of the pull-off strength, due to the surface 'uniformisation' by the bond coat. In the case of untreated surfaces and after shotblasting for $45 \mathrm{~s}$, only the coefficient of variation increased. The highest variation in the pull-off strength was obtained for milling and shotblasting in the case of repair with bond coat and for grinding and sandblasting when bond coat was not applied.

The surface roughness and the presence of the bond coat had an effect on the type of failure (Fig. 5(a)). In the case of overlays with bond coat, cohesion failures were only observed in the concrete substrate. The interface failure mode was predominant for overlays applied without the bond coat. The percentage of interface failure ranged from $50 \%$ for shotblasting to $80 \%$ for concrete without treatment. However, the pull-off strength calculated for two different modes of failure (Fig. 5(b)) showed relatively low differences for both failure modes in the case of shotblasting and milling. This confirmed that vigorous treatments like shotblasting or milling, which produce microcracks in the near-surface layer (see Table 2), may induce the 'unsoundness' of concrete. $^{18,19}$ This implies a relatively low value for pull-off strength in cohesive failure.

\section{Analysis of the effect of surface concrete treatment on the adhesion}

The results (Fig. 6) showed that relationships between surface roughness and pull-off strength does not 
Table 2. Profile analysis and SEM observation
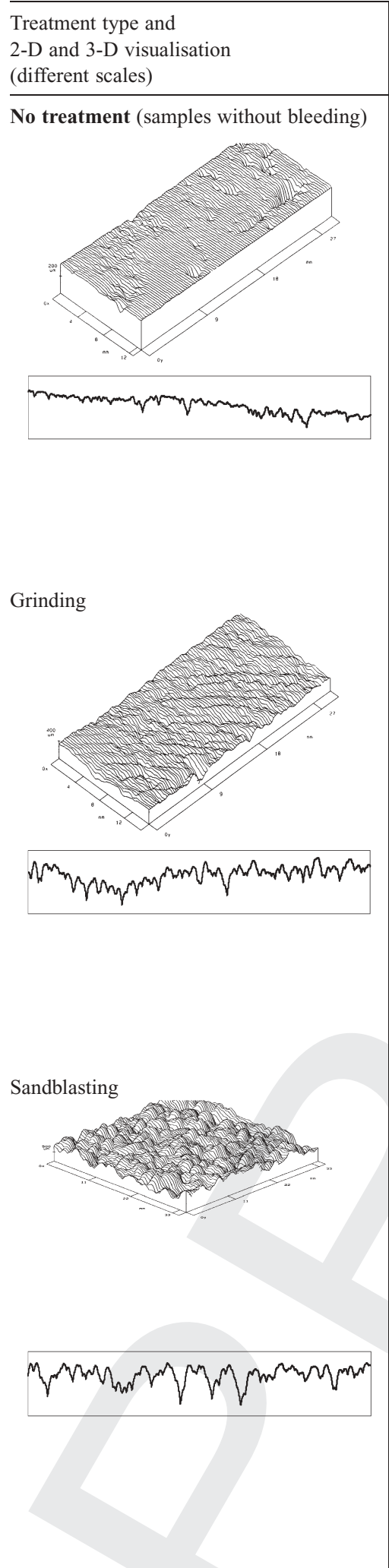

SEM magnification $25 \times($ top) and $500 \times$ (bottom)
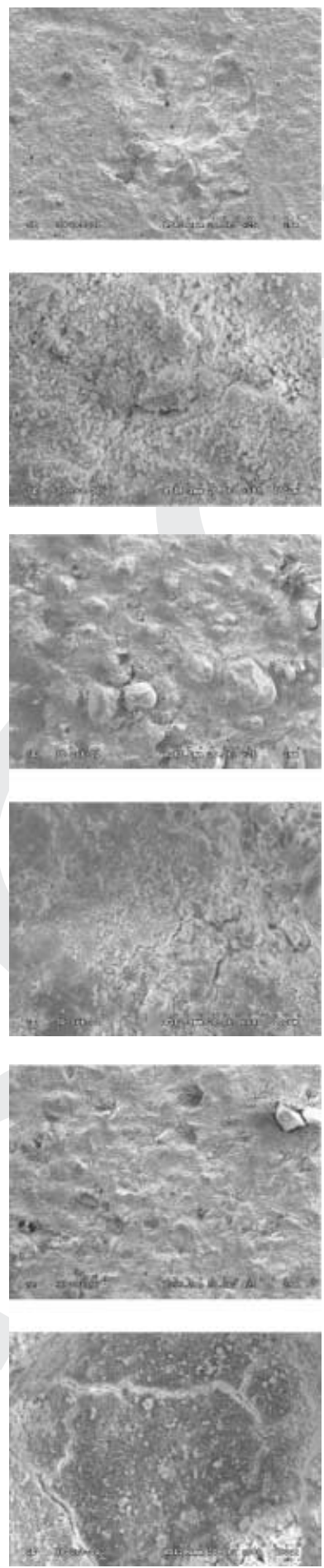

Typical roughness of formworked concrete: the flattest surface (the lowest value of waviness and roughness parameters) from tested ones, slightly undulated with shallow valleys without sharp edges (the lowest value of the parameters of Abbott's curve); at higher magnifications small micro-cracks, probably formed during concrete setting, were observed.

Low, uniform roughness higher than in the case of samples without treatment (approx. five times higher value of the waviness and roughness parameters); surface without sharp edges with rarely and nonuniformly located valleys at the surface (parameter $C_{\mathrm{F}}$ a little higher than for the surface without treatment); at higher magnifications the narrow cracks were observed.

The surface similar to that after grinding (similar value of the $W_{\mathrm{p}}$ parameter and $C_{\mathrm{R}}$ but other parameters were higher); relatively high value of $C_{\mathrm{L}}$ in comparison with the surface without treatment; shallow irregularities of surface peak-to-valley height did not exceed $1 \mathrm{~mm}$; at higher magnifications sharp edges of aggregate grains and microcracks, very often forming non-uniform network, were observed. 
Table 2. Continued

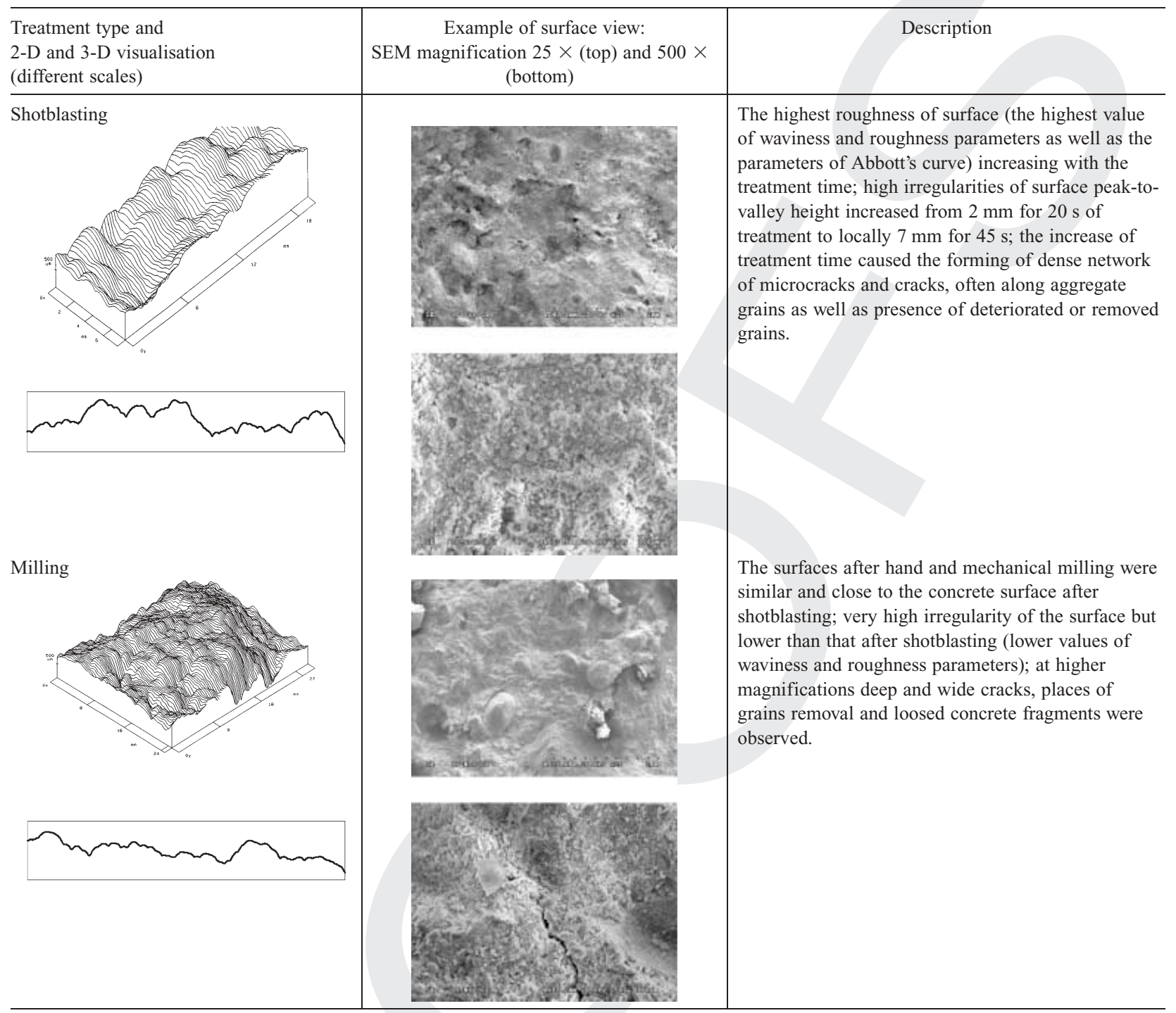

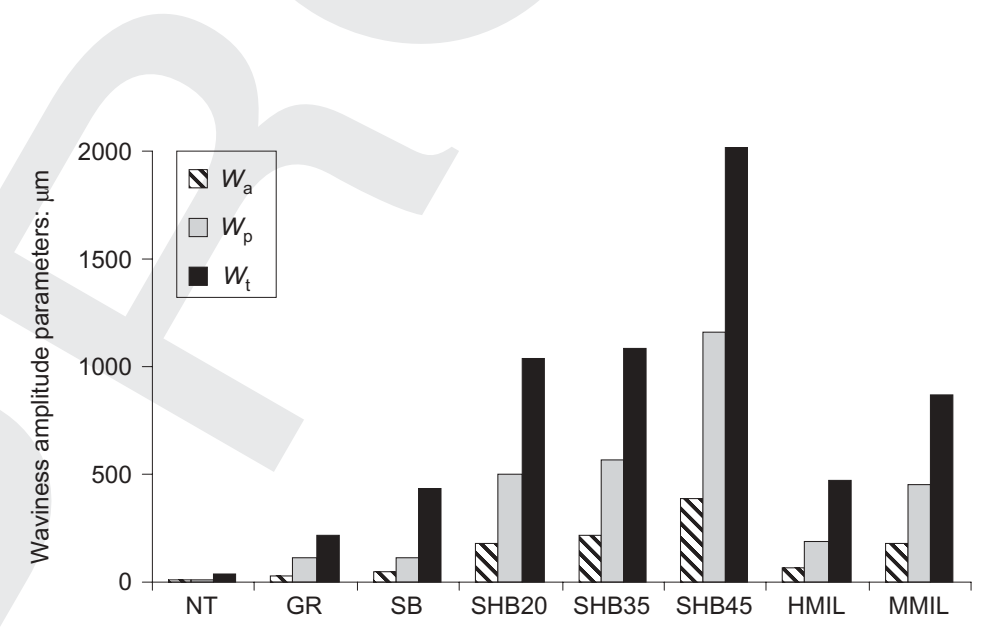

\begin{tabular}{c|r|r|r|r|r|r|r|c}
\hline & NT & GR & SB & SHB20 & SHB35 & SHB45 & HMIL & MMIL \\
\hline$W_{\mathrm{a}}$ & 5 & 32 & 49 & 180 & 215 & 386 & 70 & 179 \\
\hline$W_{\mathrm{p}}$ & 13 & 111 & 117 & 500 & 570 & 1157 & 188 & 448 \\
\hline$W_{\mathrm{t}}$ & 39 & 219 & 434 & 1036 & 1086 & 2165 & 473 & 867 \\
\hline
\end{tabular}

Fig. 2. Amplitude parameters: $W_{\mathrm{t}}, W_{\mathrm{a}}$ and $W_{\mathrm{p}}$ for waviness profile 
(a)

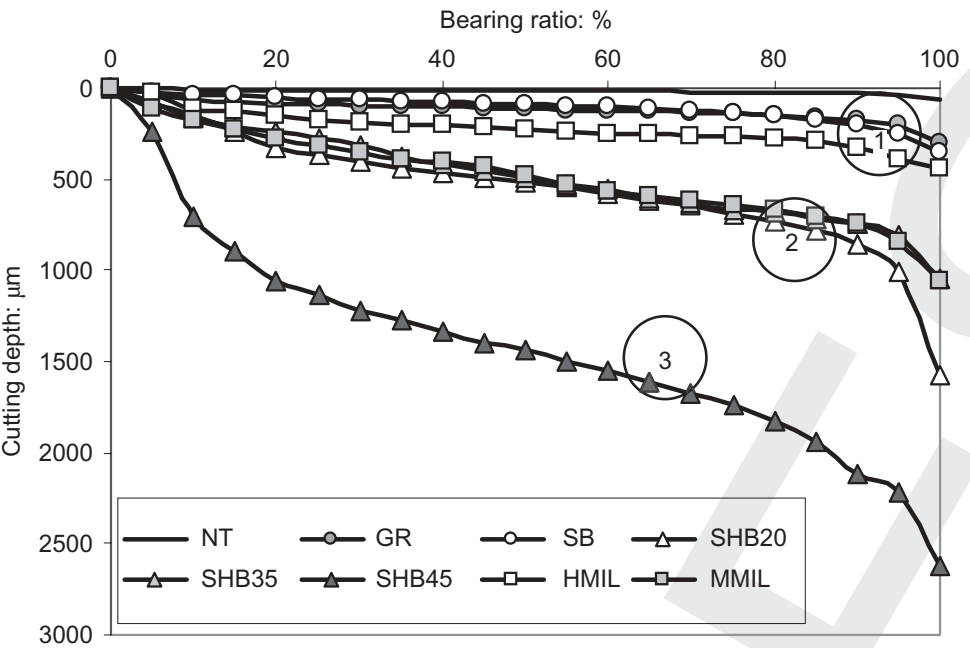

(b)

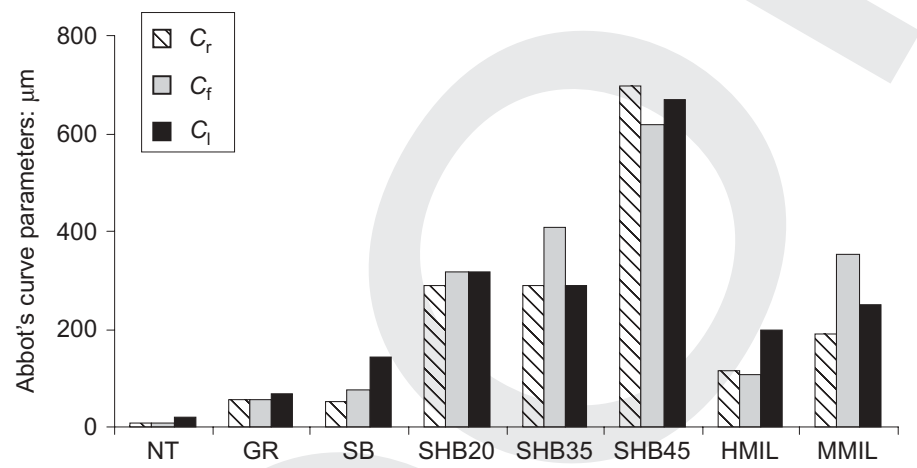

\begin{tabular}{c|r|r|r|c|c|c|c|c}
\hline & NT & GR & SB & SHB20 & SHB35 & SHB45 & HMIL & MMIL \\
\hline$C_{\mathrm{r}}$ & 6 & 57 & 50 & 291 & 289 & 698 & 116 & 188 \\
\hline$C_{\mathrm{f}}$ & 9 & 55 & 77 & 318 & 406 & 619 & 107 & 351 \\
\hline$C_{\mathrm{l}}$ & 19 & 69 & 144 & 316 & 291 & 669 & 196 & 248 \\
\hline
\end{tabular}

Fig. 3. Abbott's curve and $C_{\mathrm{L}}, C_{\mathrm{R}}$ and $C_{\mathrm{F}}$ parameters for total profile. $1,2,3=$ explanation given in text

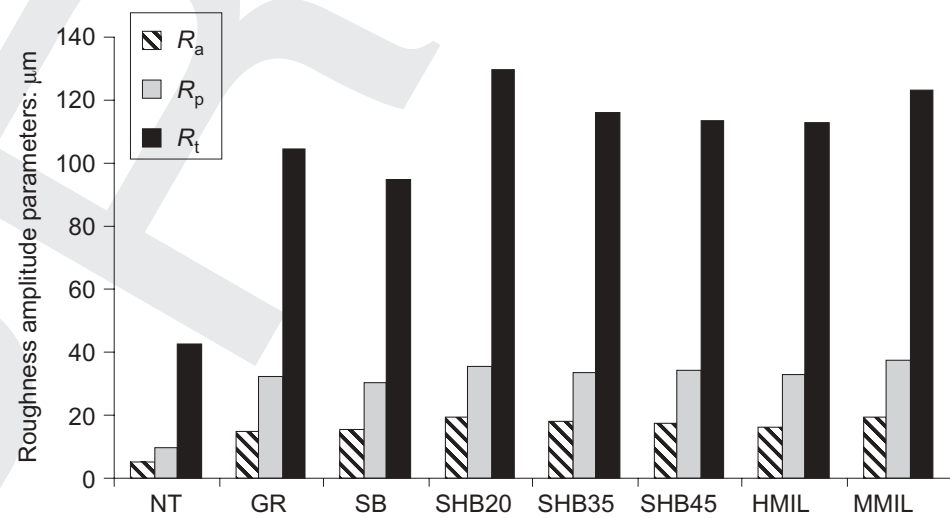

\begin{tabular}{l|r|r|r|r|r|r|r|r}
\hline & NT & GR & SB & SHB20 & SHB35 & SHB45 & HMIL & MMIL \\
\hline$W_{\mathrm{a}}$ & 5 & 15 & 15 & 19 & 18 & 17 & 16 & 19 \\
\hline$W_{\mathrm{p}}$ & 10 & 32 & 30 & 35 & 34 & 34 & 33 & 37 \\
\hline$W_{\mathrm{t}}$ & 42 & 105 & 95 & 130 & 116 & 113 & 113 & 123 \\
\hline
\end{tabular}

Fig. 4. Amplitude parameters $R_{\mathrm{a}}, R_{\mathrm{p}}$ and $R_{\mathrm{t}}$ for roughness profile 
Table 3. Pull-off strength measurements of repair mortar with and without bond coat

\begin{tabular}{l|c|c|c}
\hline \multirow{2}{*}{ Treatment type } & \multicolumn{3}{|c}{ Mean value: MPa (coefficient of variation in \%) } \\
\cline { 2 - 4 } & $\begin{array}{c}\text { Repair mortar } \\
\text { with bond coat }\end{array}$ & $\begin{array}{c}\text { Repair mortar } \\
\text { without bond coat }\end{array}$ & $f_{\mathrm{A}}{ }^{\mathrm{BC}} / f_{\mathrm{A}} \mathrm{N}-\mathrm{BC}$ \\
\hline NT & $1.92(23.4)$ & $2.28(17 \cdot 1)$ & 0.84 \\
GR & $1.82(15.9)$ & $1 \cdot 16(50 \cdot 9)$ & 1.56 \\
SB & $1.93(11.4)$ & $1.82(32 \cdot 4)$ & 1.06 \\
SHB20 & $1.68(18.5)$ & $0.78(39 \cdot 7)$ & 2.15 \\
SHB35 & $1.94(11.3)$ & $1.25(28.8)$ & 1.55 \\
SHB45 & $1.96(32.7)$ & $0.83(25.3)$ & 2.36 \\
HMIL & $1.42(12.7)$ & $1.01(40.6)$ & 1.41 \\
MMIL & $1.60(24.4)$ & $0.49(57 \cdot 1)$ & 3.23 \\
\hline
\end{tabular}

$f_{\mathrm{A}}^{\mathrm{BC}}=$ the pull-off strength for repair with bond coat

$f_{\mathrm{A}}{ }^{\mathrm{N}-\mathrm{BC}}=$ the pull-off strength for repair without bond coat exist in the case of repair systems with bond coat. For the samples without bond coat, the regression functions had relatively low correlation coefficients, ranging from $r=0.78$ for $W_{\mathrm{t}}$ up to $r=0.84$ for $W_{\mathrm{p}}$. Similar statistical significance of the relationships were obtained for parameters of Abbott's curve. The best fitting was determined for the parameter $C_{\mathrm{R}}(r=0 \cdot 84)$.

The regression functions showed, to some degree, unexpected trends. As the surface roughness increased, the pull-off strength for the systems without bond coat decreased. The most significant effect was observed for the parameters describing the height of the profile peaks. This indicates that surface roughness can be an important factor in influencing adhesion in repair systems. The crucial point is suitable rheological proper-
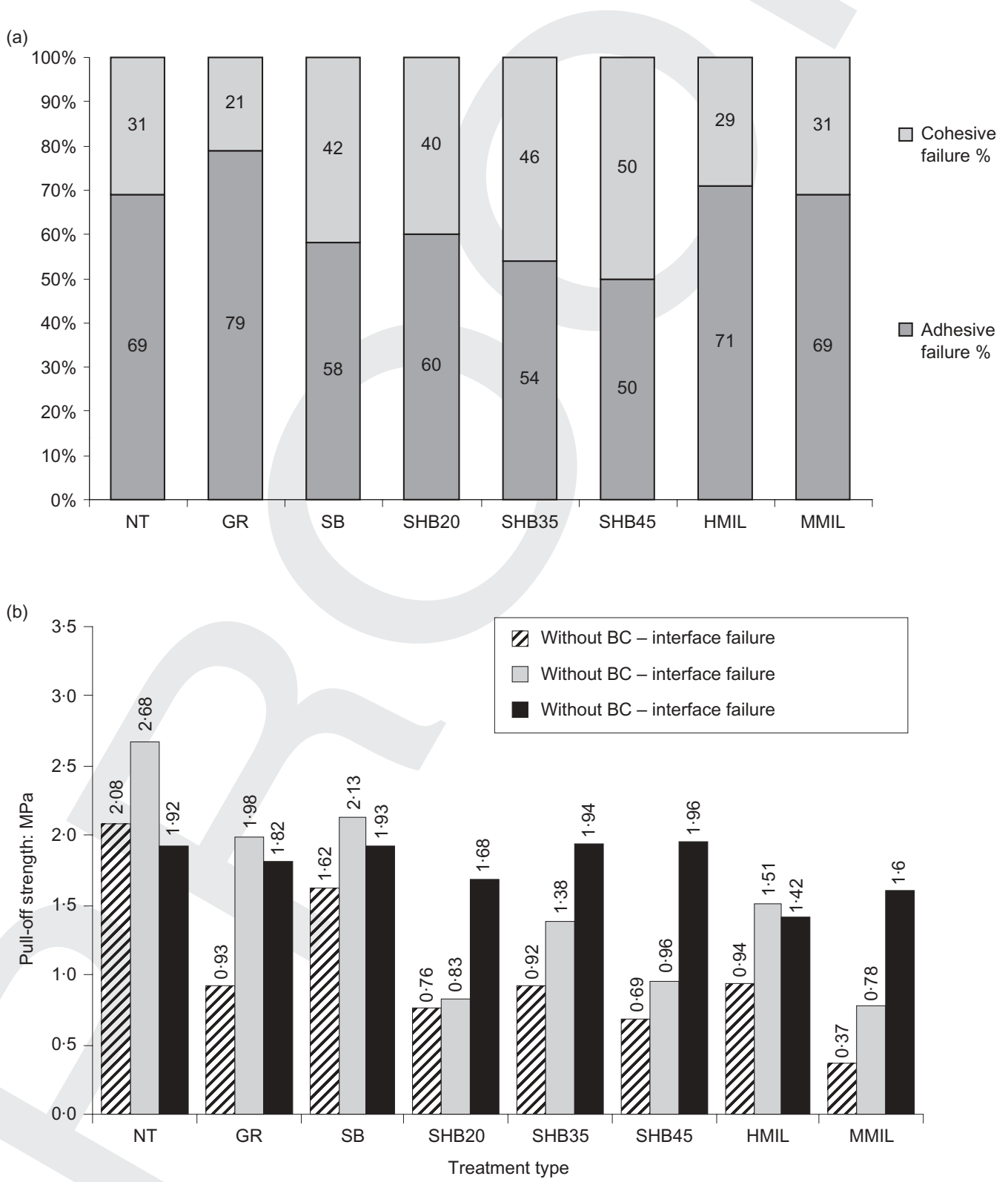

Fig. 5. Fraction of adhesive and cohesive failure for: (a) repair without bond coat; and (b) pull-off strength obtained at cohesive and adhesive failure modes. $B C=$ bond coat 
(a)

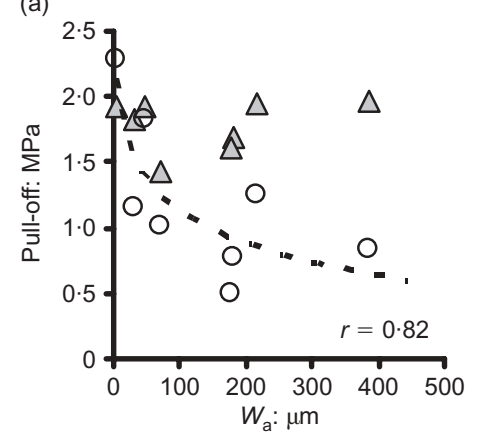

(b)

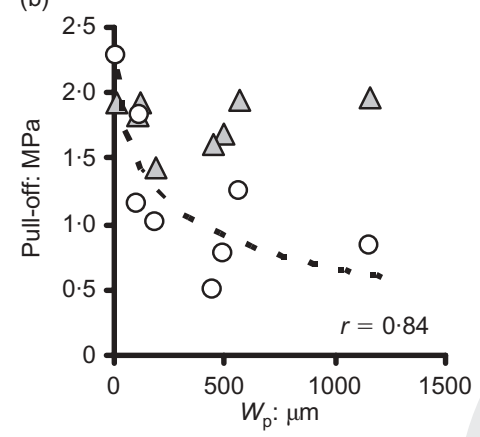

(c)

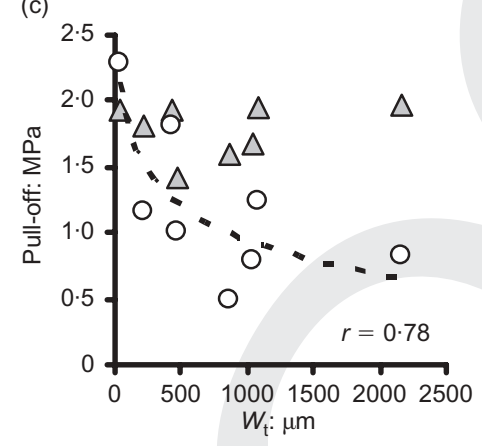

(d)

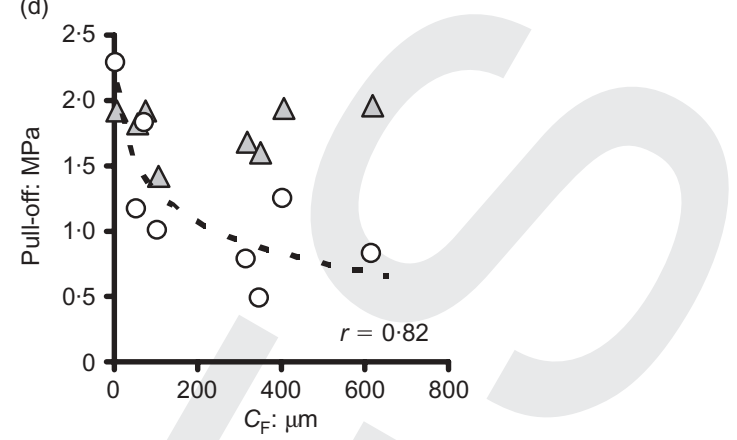

(e)

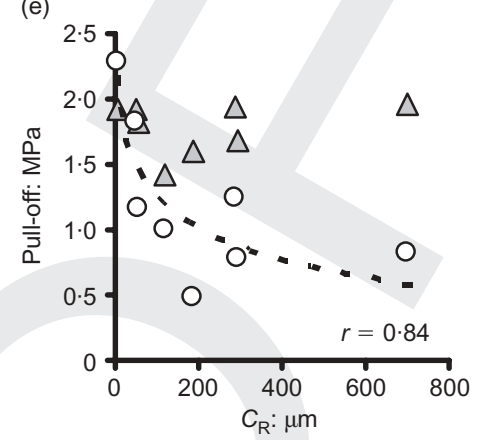

(f)

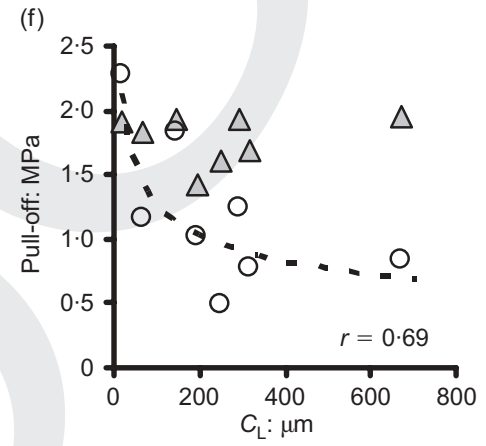

Fig. 6. Regression curves between pull-off strength and statistical and amplitude parameters of the waviness profile

ties of bond coat and/or repair mortar to fulfil irregularities at the interface zone. The repair material tested had a relatively low workability, partially due to the content of microfibres. Additionally, it was observed that the microfibres were blocked on the irregularities of the profile (Fig. 7). This caused the appearance of voids at the interface zone: an increase in roughness induces a high voids fraction (Fig. 8) The flat surfaces resulting from 'soft' treatments like sandblasting and grinding as well as surfaces without treatment, were characterised by a relatively low void content at the interface zone. For more 'aggressive' treatments, higher void content was observed. This kind of behaviour was observed also by Fukuzawa et $a l^{17}$ in the case of chipping. They have obtained a statistically significant relationship between the pull-off strength and the parameters of surface roughness for less vigorous treatments like sandblasting, disc-grinding and sandpaper polishing. The results of the pull-off strength for chipping were excluded because of their remarkably lower values in comparison with the results for the sand-

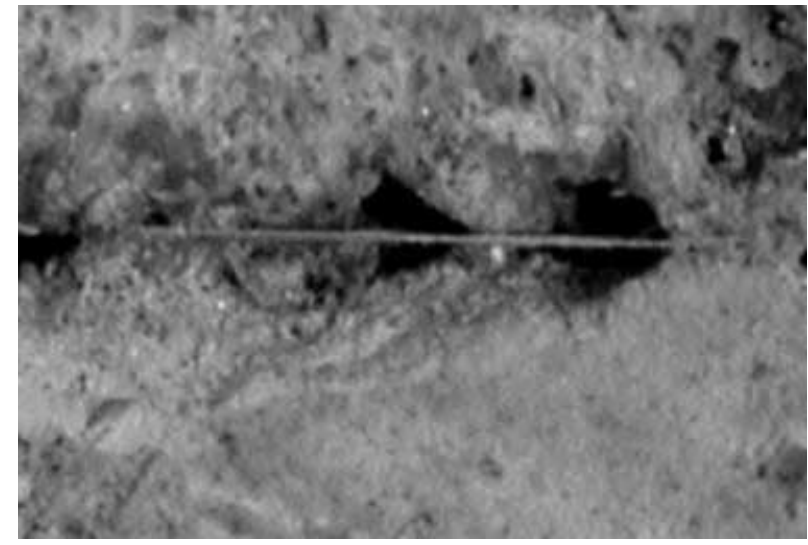

Fig. 7. View of the glass microfibre at the interface surface

blasted surface with similar roughness. The authors have suggested that the lower adhesion is due to the presence of flaws at the interface created after chipping. 

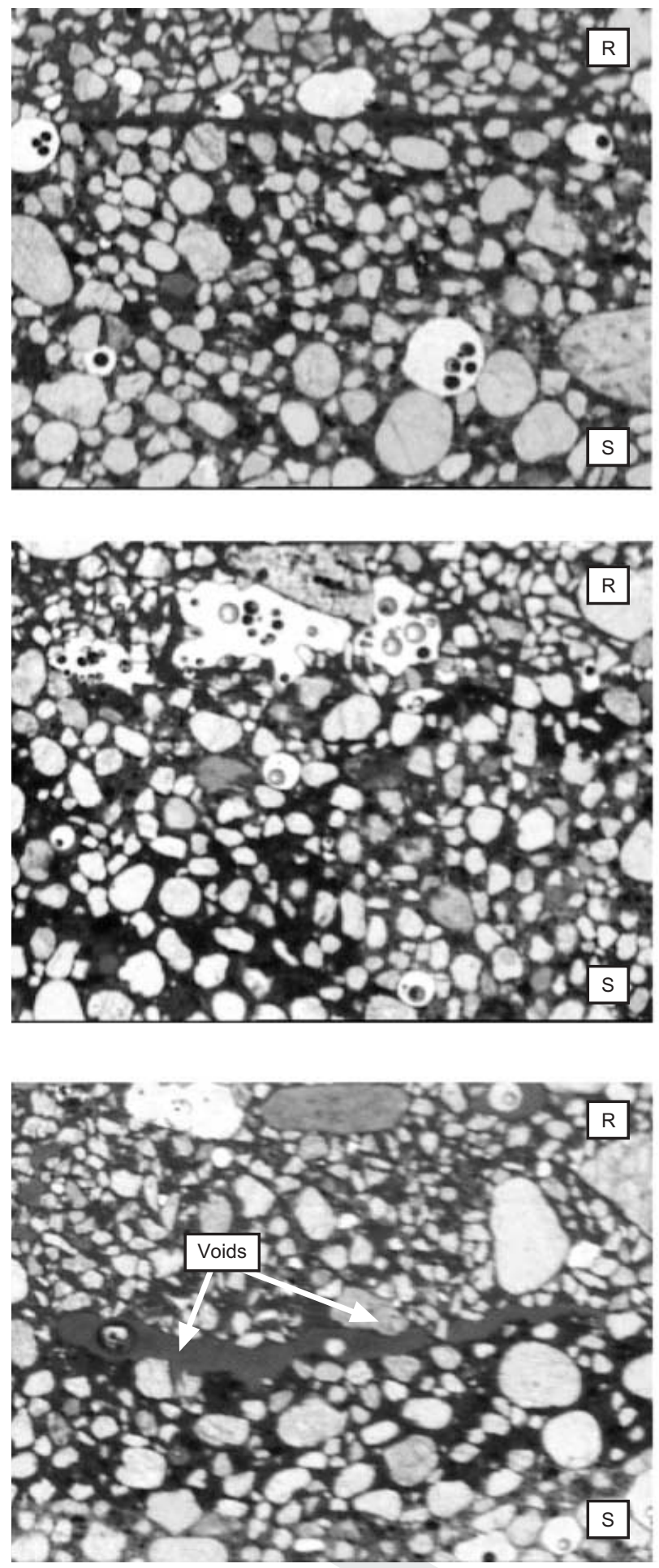
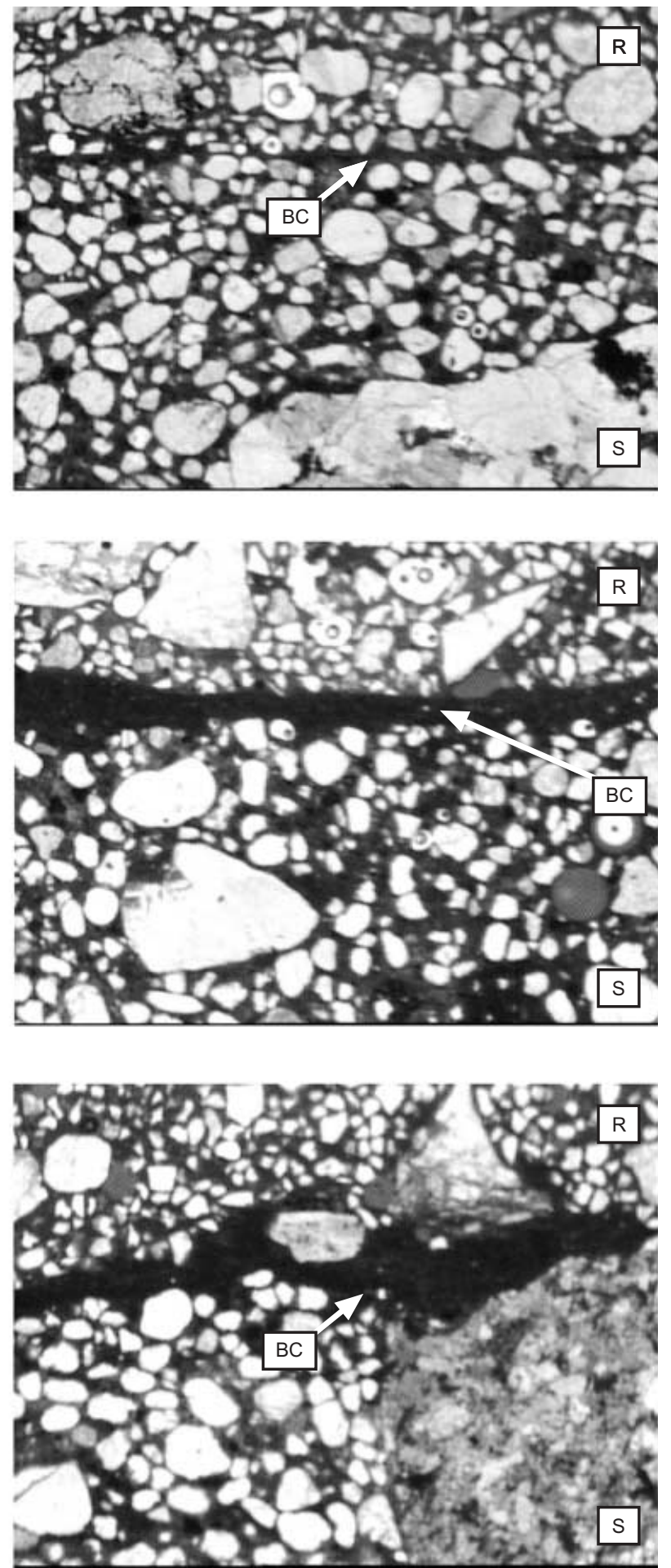

Fig. 8. View of the interface between concrete substrate and repair material with bond coat (left) and without (right): (a) without treatment; (b) sandblasting; (c) mechanical milling. $S=$ concrete substrate, $B C=$ bond coat, $R=$ repair mortar

This could confirm that some optimal threshold value of roughness exists. Additionally, for the samples after aggressive treatment, a near-surface layer of unsound concrete was observed. This microscopic observation could be related to the low value of pull-off strengths in the case of cohesive failure for samples after shotblasting and milling. It also indicates that quantitative information concerning cracks might reduce scatter in statistical regressions. The results confirmed that the creation of the adhesion in repair techniques is a complex phenomenon resulting from a synergic effect of the surface roughness of the concrete substrate, the presence of microcracks and deteriorated aggregates and the processing properties of the repair 
materials as well. The effect of lower workability of the repair material can be lowered by using treatments that give a relatively smooth surface (e.g. sandblasting) and the application of a suitable bond coat.

\section{Conclusions}

The following conclusions may be reached from the present investigations concerning the influence of surface treatment on the adhesion of repair material.

(a) The creation of the adhesion in repair system is a complex phenomenon resulted from a synergic effect of the surface roughness of concrete substrate, the presence of microcracks in the near-surface layer and deteriorated grains of aggregate as well as processing properties of the repair materials including interfacial tension between the bond coat and/or repair materials.

(b) In the case of the tested repair systems, the roughness of concrete substrate influences the adhesion mainly in the case of overlays applied without bond coat; the bond coat unified the adhesion level irrespective of the surface roughness. This indicates that suitable rheological properties of bond coat and/or repair mortar are necessary to develop good bond by filling surface irregularities and bridging the cracks and loose concrete pieces.

(c) The number and the size of cracks are dependent on the surface treatment: shotblasting and milling produce more cracks and any increase in duration of the treatment induces higher deterioration of the near-surface layer.

(d) The surface roughness and the presence of bond coat have an effect on the type of failure. Cohesion failure is more frequent in the case of the use of a bond coat and is directly influenced by the microcracks.

(e) The treatment of the concrete surface has a profitable impact when it is used to clean a concrete surface from bond-detrimental layers or to remove unbound concrete pieces. As the 'aggressiveness' of surface treatment increases (from sandblasting to milling, through shotblasting,) the necessity of using a bond coat increases.

From the results of the surfometry and profilometry analysis, the following conclusions can be formulated.

(a) Amplitude parameters are able to quantitatively characterise the profile by analysing holes, peaks, frequencies and amplitudes of the irregularities The difference between the profiles is more effective at the level of waviness than roughness: on its own waviness profile, roughness amplitude is not statistically different for the different profiles.

(b) $X_{\text {a }}$ parameter (arithmetic mean of the departure of the profile from the mean line) and the parameter $C_{\mathrm{F}}$ deduced from Abbott's curve are the most discriminating parameters for the comparison of surface preparation techniques.

(c) Taking into account the waviness parameters $W_{\mathrm{a}}$, $W_{\mathrm{p}}$ and $W_{\mathrm{t}}$ as well as the parameters of Abbott's curve, the surface treatments can be classified in order of their 'aggressiveness' as follows (least aggressive first): grinding, sandblasting, hand milling, mechanical milling, shotblasting.

(d) The results of this work show also the need for improvement of the profilometry device used to test rough concrete surface by developing a new type of stylus or the use of a non-contact indicator.

\section{Acknowledgements}

The authors are grateful to Professor L. Czarnecki, head of the Building Materials Engineering Division at the Warsaw University of Technology and Professor R. Degeimbre, head of the Building Materials Laboratory at the University of Liege, for their valuable discussion and remarks. The authors express their sincere appreciation to Professor J. Bozet, head of the Mechanical Engineering and Tribology Department and M. Nélis, research engineer, for the opportunity to use the SURFASCAN test device. The research project was financially supported by the Government of Poland (KBN) and the Regional Government of Wallonia (DRI), Belgium. Part of the experiments have been done in the framework of a project granted by the Polish Scientific Research Committee, grant number KBN 5T07E06622.

\section{References}

1. Czarnecki L. and Emmons P. H. Repair and Protection of Concrete Structures (in Polish). Polski Cement, Krakow, 2002.

2. Czarnecki L., Vaysburd A. M., Mailvaganam N. P., EmMONS P. H. and MCDonald J. E. Repair and rehabilitation of structures-some random thoughts. Indian Concrete Journal, 2000, 74, 13-20.

3. Czarnecki L., Garbacz A., Łukowski P. and Clifton J. R. Polymer Composites for Repairing of Portland Cement Concrete: Compatibility Project. United States Department of Commerce, National Institute of Standards and Technology, Gaithersburg, 1999, NIST Report (NISTIR 6394).

4. SASSE H. R. and CZARneCKI L. Repair and protection of concrete structures in the light of European standard prEN 1504-10. Building Materials1999, 7, 30-33, (in Polish).

5. American Concrete Institute. ACI Manual of Concrete Practice, Part 4: Concrete Repair Guide. ACI, 1998, ACI Committee 546, $41 \mathrm{pp}$.

6. Slater A. Simple guidelines to better surface preparation. Concrete Repair Bulletin, 2001, Jan./Feb., 4-5.

7. Building Research Institute. Guidelines for Technical Approval-ZUAT-15/VI.02 Products for Repair of Deteriorated Concrete Structures (in Polish). Building Research Institute, EOTA member, Warszawa, 1997.

8. Belgian Guidelines G0007: Agreement and Certification Guidelines for Hydraulic Binder-Based Repair Mortars. Belgian Union for Technical Agreement in Construction (UBAtc), Sector 
Civil Engineering, Walloon Ministry of Equipment and Transportation, Liège, 2002.

9. Fiebrich M. H. Influence of the surface roughness on the adhesion between concrete and gunite mortars overlays. Proceedings of the 2nd Bolomey Workshop on Adherence of Young and Old Concrete, Wittmann, Aedification Verlag, Unterengstringen, 1994, 107-114.

10. Courard L. Parametric study for the creation of the interface between concrete and repairs products. Materials and Structures, 2000, 33, 65-72.

11. Courard L. Evaluation of the thermodynamic properties of concrete substrates and cement slurries modified with admixtures. Materials and Structures, 2002, 35, 149-155.

12. Courard L. Contribution à l'Analyse des Paramètres Influençant la Création de l'Interface Entre un Béton et un Système de Réparation. Appétence et Adhérence: Cause et Effet d'une Liaison. $\mathrm{PhD}$ thesis, Université de Liège, Collection des Publications de la Faculté des Sciences Appliquées, 1999, No. 192, 213 pp. (in French).

13. Austin S., Robins P. and PAN Y. Tensile bond testing of concrete repairs. Materials and Structures, 1995, 28, 249-259.

14. Czarnecki L., Garbacz A. and Kostana K. The effect of concrete surface roughness on adhesion in industrial floor systems. Proceedings of the 5th Colloquium Industrial Floors, Esslingen, 2003.

15. MackowsKi R. The effect of concrete surface treatment on the quality of the concrete structure repair. Proceedings of the 10th Conference on Corrosion and Durability of structures-Kontra 2000, Zakopane, 2000, pp. 221-226, (in Polish).

16. Silfwerbrand J. and Paulsson J. Better bonding of bridge deck overlays. Concrete International, 1998, 20, No. 10, 56-61.

17. Fukuzawa K., Mitsui M. and Numao T. Surface roughness indexes for evaluation of bond strengths between CRFP sheet and concrete. Proceedings of the 10th International Congress on
Polymers in Concrete-ICPIC 2001, Honolulu, 2001, paper no. 12.

18. SilfFerbRand J. Improving concrete bond in repaired bridge decks. Concrete International 12, 61-66.

19. Courard L. and Bissonnette B. Quantification of the influence of concrete removal techniques upon residual cracking. Concrete International (submitted for publication).

20. Pretorius J. and Kruger D. The influence of surface roughness on the bond strength of concrete repairs. Proceedings of the 10th International Congress on Polymers in ConcreteICPIC 2001, Honolulu, 2001, paper no. 13.

21. Courard L. and Nelis M. Surface analysis of mineral substrates for repair works: roughness evaluation by profilometry and surfometry analysis. Magazine of Concrete Research, 2003, 55, No. 4, 355-366.

22. Courard L. Parametric definition of sandblasted and polished concrete surfaces. Proceedings of the 9th International Congress on Polymers in Concrete, Bologna, 1998, pp. 771-778.

23. Czarnecki L., Garbacz A. and Kurach J. On the characterization of polymer concrete fracture surface. Cement and Concrete Composites, 2001, 23, 399-409.

24. Perez F., Bissonnette B. and Courard L. Outils de caractérisation paramétrique de la rugosité des surfaces en béton: nouveaux développements. Journées Scientifiques du $R F^{2} B, 25-26$ August, Sherbrooke, 2003.

25. Sherrington I. and Smith E. H. Modern measurement techniques in surface metrology—part I: stylus instruments, electron microscopy and non-optical comparators. Wear, 1988, 125, 271-288.

Discussion contributions on this paper should reach the editor by ?? 